\title{
APRENDIZAGEM DOCENTE NO ÂMBITO DO PIBID/FÍSICA: A VISÃO DOS BOLSISTAS DE INICIAÇÃO À DOCÊNCIA
}

\author{
Luiz Marcelo Darroz* \\ Clóvis Milton Duval Wannmacher**
}

RESUMO: Este artigo apresenta os resultados de uma pesquisa de cunho qualitativo que objetivou identificar indícios da ocorrência da aprendizagem docente nos licenciandos de física participantes do Programa Institucional de Bolsa de Iniciação à Docência dos subprojetos de física do Rio Grande do Sul. A coleta de dados ocorreu por meio de entrevistas semiestruturadas gravadas em áudio e posteriormente transcritas. A análise dos dados deu-se a partir dos materiais coletados, dos quais se realizou uma análise textual discursiva que tinha como categorias a priori os cinco focos da aprendizagem docente. Os resultados indicam que a participação nas atividades do Pibid/Física pode promover a aprendizagem docente, uma vez que elementos dos cinco focos foram identificados nas falas dos bolsistas de iniciação à docência.

Palavras-chave: Pibid/Física. Bolsistas de iniciação à docência. Aprendizagem docente. Focos de aprendizagem docente.

\section{APRENDIZAJE DOCENTE EM EL PIBID/FÍSICA: LA VISIÓN DE LOS BECÁRIOS DE INICIACIÓN A LA DOCENCIA}

RESUMEN: Este artículo presenta los resultados de una investigación cualitativa con el objetivo de identificar indicios de ocurrencia de aprendizaje docente en los licenciandos de física participantes del Programa Institucional de Becas de Iniciación a la Docencia de los sub-proyectos de física en el Rio Grande do Sul, Brasil. La recopilación de datos ocurrió por medio de entrevistas semiestructuradas grabadas en audio y posteriormente transcriptas. El análisis de los datos se hizo a partir de los materiales recogidos, de los cuales se realizó un análisis textual discursivo que tenía como categorías a priori los cinco focos de aprendizaje docente. Los resultados indican que la participación en las actividades del Pibid/Física puede promover el aprendizaje docente, una vez que elementos de los cinco focos fueron identificados en las declaraciones de los becarios de iniciación a la docencia.

Palabras clave: Pibid/Física. Becarios de iniciación a la docencia. Aprendizaje docente. Focos de aprendizaje docente. 


\section{TEACHER LEARNING IN PIBID/PHYSICS SCOPE:}

\section{TEACHING INITIATION FELLOWS' VIEW}

ABSTRACT: This paper presents the results of a qualitative research that aimed to identify evidence of teacher learning's occurrence among Physics graduates participating in the Institutional Scholarship Program for Teaching Initiation (Pibid) in the Physics subprojects in the state of Rio Grande do Sul, Brazil. Data collection was performed through semi-structured interviews that were audio recorded and later transcribed. Data analysis was performed from the materials collected, from which textual discourse analysis was performed with the five teacher's learning focuses as a priori categories. Results indicate that the participation in Pibid/Physics activities may promote teacher learning, since elements from the five focuses were identified in the speech of teacher initiation fellows.

Keywords: Pibid/Physics. Teacher initiation fellows. Teacher learning. Teacher learning focuses. 


\section{INTRODUÇÃO}

De acordo com Nóvoa (2009), os cursos de formação de professores devem partir de situações concretas do ambiente escolar, onde ocorra a promoção da articulação entre teoria e prática. Nas palavras do autor,

[...] la formación de profesores ganaría mucho si se organizase, preferentemente, en torno a situaciones concretas de fracaso escolar, de problemas escolares o de programas de acción educativa. Y si inspirase junto a los futuros profesores la misma obstinación y perseverancia que los médicos revelan en la búsqueda de las mejores soluciones para cada caso (NÓVOA, 2009, p. 209).

No entanto, o que tem se percebido nos cursos de licenciatura é a concentração de conteúdos teóricos na sua fase inicial, sendo, somente a partir da metade, apresentadas as disciplinas destinadas à construção dos conhecimentos pedagógicos e à prática de ensino. As ações práticas no ambiente escolar, como o estágio supervisionado, quase sempre ocorrem de forma fragmentada no fim do curso e têm como objetivo principal aplicar os conhecimentos adquiridos no decorrer da graduação.

Para Tardif (2000, p. 18), essas estruturas são "idealizadas segundo um modelo aplicacionista do conhecimento", que é justamente a concentração de conteúdos nos primeiros anos da formação, constituídos de "conhecimentos proposicionais". Esse modelo impossibilita, muitas vezes, que os licenciandos compreendam as relações humanas que se constroem na dinâmica interativa e peculiar do ambiente escolar, movidas pelos processos de aprender e de ensinar, e que são elementos essenciais ao desempenho profissional do docente. Isto é, essa estrutura dificulta que as necessidades do licenciando sejam supridas durante a sua formação, de modo que ele acaba saindo da universidade sem uma noção concreta da vivência escolar, sentindo-se despreparado para assumir sua profissão (LEVY; SANMARTÍ PUIG, 2001).

O Programa Institucional de Bolsas de Iniciação à Docência (Pibid), instituído pelo Ministério da Educação e coordenado pela Diretoria de Educação Básica Presencial (DEB), da Coordenação de Aperfeiçoamento de Pessoal de Nível Superior (Capes), surge como opção para minimizar o distanciamento entre o que é estudado nos bancos universitários e a prática no ambiente escolar. O programa prevê bolsas para que estudantes de licenciatura, orientados por um professor de universidade conveniada e um professor experiente da educação básica, realizem ações e/ou projetos em instituições da rede pública da educação básica, atuando diretamente no seu futuro campo profissional (CAPES, 2013). Nesse sentido, espera-se que, ao serem inseridos no cotidiano escolar, os acadêmicos participantes do Pibid possam planejar e participar de experiências metodológicas e didáticas, bem como de práticas docentes de caráter inovador e interdisciplinar, buscando superar problemas identificados nos processos de ensinar e de aprender.

Ao longo dessa formação e da atuação nas escolas, os estudos devem 
ser direcionados aos problemas observados no cotidiano, podendo o acadêmico vivenciar situações escolares reais, em busca de respostas para um melhor desempenho nos processos de ensinar e de aprender, por meio da reflexão na/sobre/ para a prática, concepção que vai ao encontro das ideias de Tardif (2007). Segundo ele,

[...] a prática pode ser vista como um processo de aprendizagem por meio do qual os professores retraduzem sua formação e a adaptam à profissão, eliminando o que lhes parece inutilmente abstrato ou sem relação com a realidade vivida e conservando o que pode servir-lhes de uma maneira ou de outra (TARDIF, 2007, p. 53).

Diante desse contexto, apresentam-se, neste trabalho, os resultados de uma pesquisa na qual se busca perceber a aprendizagem docente adquirida pelos licenciandos que participam do Pibid, na categoria de subprojetos de física, do Estado do Rio Grande do Sul.

\section{Contextos teóricos e metodológicos da pesquisa}

A pesquisa aqui relatada trata-se de um estudo de cunho qualitativo que descreve as experiências vivenciadas por 32 licenciandos em física que, na época da coleta de dados, participavam dos subprojetos do Pibid/Física na condição de bolsistas de iniciação à docência de 15 subprojetos desenvolvidos em 14 instituições de ensino superior do Rio Grande do Sul. Neste estudo, buscou-se identificar as aprendizagens docentes dos participantes ao vivenciarem as atividades desenvolvidas no programa. Isto é, procurou-se observar o que esse grupo de sujeitos vivenciou no decorrer das ações, como as vivenciou e se essa vivência proporcionou indícios de aprendizagem docente.

A coleta de dados que constitui o corpus da pesquisa ocorreu entre março e abril de 2015 e fez uso de entrevistas semiestruturadas. A opção pela entrevista semiestruturada deu-se porque, segundo Triviños (1987, p. 146), esse tipo de metodologia tem como característica questionamentos básicos apoiados em teorias e hipóteses que se relacionam ao tema da pesquisa. Conforme o autor, os questionamentos dão frutos a novas hipóteses surgidas com base nas respostas dos informantes, o que "favorece não só a descrição dos fenômenos sociais, mas também sua explicação e a compreensão de sua totalidade”, além de manter a presença consciente e atuante do pesquisador no processo de coleta de informações (TRIVIÑOS, 1987, p. 152).

As perguntas que compunham a entrevista semiestruturada (tabela 1) foram elaboradas e dirigidas, principalmente, para fornecer informações quanto à aprendizagem docente, pautando-se em aspectos revelados pelos focos da aprendizagem docente (FADs) (ARRUDA; PASSOS; FREGOLENTE, 2012). 
Tabela 1 - Perguntas que compuseram as entrevistas semiestruturadas

\begin{tabular}{|c|c|c|}
\hline Foco & Pergunta & Objetivo da pergunta \\
\hline $\begin{array}{l}\text { Foco } 1 \\
\text { Interesse pela } \\
\text { docência }\end{array}$ & $\begin{array}{l}\text { Como você avalia } \\
\text { a sua participação } \\
\text { nas atividades } \\
\text { desenvolvidas no } \\
\text { programa? }\end{array}$ & $\begin{array}{l}\text { Identificar se os bolsistas de iniciação } \\
\text { à docência demonstravam motivação, } \\
\text { empolgação e interesse ao experimenta- } \\
\text { rem atividades desenvolvidas no ambiente } \\
\text { escolar. }\end{array}$ \\
\hline $\begin{array}{l}\text { Foco } 2 \\
\text { Conhecimen- } \\
\text { to prático da } \\
\text { docência }\end{array}$ & $\begin{array}{l}\text { Quais as princi- } \\
\text { pais atividades } \\
\text { desenvolvidas no } \\
\text { subprojeto Pibid/ } \\
\text { Física de que } \\
\text { participa como } \\
\text { bolsista de inicia- } \\
\text { ção à docência? }\end{array}$ & $\begin{array}{l}\text { Evidenciar repertório de experiências } \\
\text { didáticas e pedagógicas vivenciadas pelos } \\
\text { bolsistas de iniciação à docência no am- } \\
\text { biente escolar. }\end{array}$ \\
\hline $\begin{array}{l}\text { Foco } 3 \\
\text { Reflexão sobre } \\
\text { a docência }\end{array}$ & $\begin{array}{l}\text { Como ocor- } \\
\text { rem a análise e } \\
\text { a reflexão das } \\
\text { implementações } \\
\text { das atividades } \\
\text { desenvolvidas no } \\
\text { ambiente escolar } \\
\text { por meio do } \\
\text { programa? }\end{array}$ & $\begin{array}{l}\text { Perceber se os bolsistas participaram de } \\
\text { atividades que os possibilitaram analisar a } \\
\text { experiência vivenciada e, partindo dessa } \\
\text { análise, buscar soluções para os problemas } \\
\text { detectados. }\end{array}$ \\
\hline $\begin{array}{l}\text { Foco } 4 \\
\text { Comunidade } \\
\text { docente }\end{array}$ & $\begin{array}{l}\text { Existe algum } \\
\text { espaço no pro- } \\
\text { grama destinado } \\
\text { à reflexão em } \\
\text { conjunto sobre } \\
\text { as atividades } \\
\text { desenvolvidas na } \\
\text { escola? }\end{array}$ & $\begin{array}{l}\text { Identificar se os bolsistas de iniciação parti- } \\
\text { cipam de atividades desenvolvidas em uma } \\
\text { comunidade docente e, através delas, apren- } \\
\text { dem as práticas e a linguagem da docência } \\
\text { com outros professores ou futuros profes- } \\
\text { sores, assimilando valores dessa comunida- } \\
\text { de e desenvolvendo a reflexão coletiva. }\end{array}$ \\
\hline $\begin{array}{l}\text { Foco } 5 \\
\text { Identidade } \\
\text { docente }\end{array}$ & $\begin{array}{l}\text { Você já se sente } \\
\text { professor? }\end{array}$ & $\begin{array}{l}\text { Perceber se houve a construção de uma } \\
\text { identidade docente nos bolsistas de inicia- } \\
\text { ção à docência mediante a sua participação } \\
\text { nas atividades desenvolvidas no programa. }\end{array}$ \\
\hline
\end{tabular}


Para Arruda, Passos e Fregolente (2012, p. 44), os FADs poderão ser aplicados em diferentes configurações de aprendizagem e se referem às diversas situações em que a aprendizagem docente pode ocorrer, como em "disciplinas da licenciatura, no estágio supervisionado, em cursos de formação em serviço ou outras configurações menos formais e em programas como o Pibid, etc.”.

Nesse sentido, a primeira questão que compôs a entrevista estava relacionada com o Foco 2: Quais as principais atividades desenvolvidas no subprojeto Pibid/ Física de que participa como bolsista de iniciação à docência? Tardif e Raymond (2000) entendem que atividades no ambiente escolar desenvolvem conhecimentos de casos e constroem um vasto repertório de experiências didáticas e pedagógicas, pois a carreira docente

é também um processo de socialização, isto é, um processo de marcação e de incorporação dos indivíduos às práticas e rotinas institucionalizadas das equipes de trabalho. Ora, essas equipes de trabalho exigem que os indivíduos se adaptem a essas práticas e rotinas, e não o inverso. Do ponto de vista profissional e da carreira, saber como viver numa escola é tão importante quanto saber ensinar na sala de aula. Nesse sentido, a inserção numa carreira e o seu desenrolar exigem que os professores assimilem também saberes práticos específicos aos lugares de trabalho, com suas rotinas, valores, regras, etc. (TARDIF; RAYMOND, 2000, p. 217)

A segunda questão - Como você avalia a sua participação nas atividades desenvolvidas no programa? - refere-se ao Foco 1, pois se acredita que a autoavaliação dos bolsistas nas atividades desenvolvidas no programa pode demonstrar o seu interesse, a sua curiosidade e a sua motivação em aprender sobre a docência. Como defende Sacristán (2000, apud PIRATELO, PASSOS; ARRUDA, 2014), “os professores, por mais que pareça estranho, são pessoas que sentem e que querem [...] não só pensam". Ao se motivarem pela profissão, os bolsistas adquirem saberes oriundos da experiência vivenciada e que podem servir de base para sua futura atuação profissional.

Nóvoa (1999, apud DEBALD; ROVARIS, 2007) salienta que a bagagem essencial de um professor se adquire na escola, por meio da experiência e da reflexão sobre a experiência. De acordo com o autor,

[...] a formação deve contribuir para criar nos futuros professores hábitos de reflexão e autorreflexão que são essenciais numa profissão que não se esgota em matrizes científicas ou mesmo pedagógicas, e que se define, inevitavelmente, a partir das referências pessoais (apud DEBALD; ROVARIS, 2007, p. 193).

Assim, a terceira pergunta - Como ocorrem a análise e a reflexão das implementacõos das atividades desenvolvidas no ambiente escolar por meio do programa? - visava verificar se os bolsistas participaram de atividades que os possibilitaram analisar a experiência vivenciada e, partindo dessa análise, buscar soluções para os problemas detectados, ou seja, consistia em encontrar indícios da aprendizagem docente relativa ao Foco 3. 
Em relação ao Foco 4, dirigiu-se a seguinte pergunta aos bolsistas: Existe algum espaço no programa destinado à reflexão em conjunto sobre as atividades desenvolvidas na escola? Tal indagação fundamentou-se em Nóvoa (1999), que acredita que a aprendizagem docente é efetivada na integração de modos coletivos de trabalho, na partilha de experiências e na colaboração entre os docentes. Em vista disso, o autor avalia que

[...] é preciso inscrever rotinas de funcionamento, modos de decisão e práticas pedagógicas que apelem à correponsabilização e à partilha entre colegas. É fundamental encontrar espaços de debate, de planificação e de análise, que acentuem a troca e a colaboração entre os professores (NÓVOA, 1999, p. 8).

Corroborando o entendimento de Nóvoa (1999) sobre a socialização de experiências entre os pares, Tardif (2012) considera a ação docente como uma prática essencialmente interativa. Para o autor, o professor nunca age sozinho:

Ele se encontra em interação com outras pessoas, a começar pelos alunos. A atividade docente não é exercida sobre um objeto, sobre um fenômeno a ser conhecido ou uma obra a ser produzida. Ela é realizada concretamente numa rede de interações com outras pessoas, num contexto onde o elemento humano é determinante e dominante e onde estão presentes símbolos, valores, sentimentos, atitudes, que são passíveis de interpretação e decisão que possuem, geralmente, um caráter de urgência (TARDIF, 2012, p. 49-50).

Buscando evidenciar a aprendizagem docente relacionada com o Foco 5, indagou-se aos bolsistas se eles já se sentiam como professores, buscando verificar se no decorrer das atividades desenvolveram uma identidade docente. Para essa questão, tomou-se como referencial o entendimento de Pimenta (1997, p. 7), ao afirmar que

[...] uma identidade profissional se constrói a partir da significação social da profissão; da revisão constante dos significados sociais da profissão, da revisão das tradições. Do confronto entre as teorias e as práticas, da análise sistemática das práticas à luz das teorias existentes da construção de novas teorias, constrói-se, também, pelo significado que cada professor, enquanto ator e autor, confere à atividade docente no cotidiano a partir de seus valores, de seu modo de situar-se no mundo, de sua história de vida, de suas representações, de seus saberes, de suas angústias, do sentido que tem em sua vida: o ser professor.

A respeito da formação da identidade docente, Nóvoa (2009) salienta que é impossível separar as dimensões pessoal e profissional. Assim, os docentes ensinam o que são e naquilo que são se encontra o que ensinam. Nesse sentido, consolidar uma identidade docente no decorrer da formação de professores pode proporcionar uma maior segurança aos licenciandos em sua futura atuação.

Além dessas cinco questões, os estudantes foram interpelados sobre a importância da bolsa que recebiam e sobre a sua opinião acerca do ambiente escolar como local de formação docente. Por fim, todos foram convidados a falar sobre o que consideravam ter aprendido com essas experiências de docência. 
Todos os entrevistados são licenciandos em física e participam, em média, há dois anos e meio do Pibid/Física. Ao longo deste trabalho, para manter o seu anonimato, eles são mencionados no gênero masculino e nominados por B1, B2, B3, B4, ..., B32. As entrevistas foram transcritas e submetidas aos procedimentos da Análise Textual Discursiva (ATD) apresentados por Moraes (2003). Nesse instrumento analítico, o material de análise é denominado de corpus, tendo, no caso deste texto, sido produzido especificamente para este trabalho.

A ATD inicia-se com a fragmentação do corpus, ou seja, nessa etapa, o texto analisado é desmontado/fragmentado em unidades de significado - a unitarização. A unitarização ganha sentido dentro da pesquisa quando encaminha o texto para a categorização, em que as unidades de significado são agrupadas de acordo com critérios semânticos, isto é, fragmentos que explicitam compreensões semelhantes. Logo, a categorização apresenta uma função classificatória (CRESWELL, 2014). As categorias constituem elementos de organização do novo texto que se pretende escrever, de modo que é a partir das categorias que se produzirão as descrições e interpretações do material analisado. Para este trabalho, os FADs foram adotados como categorias a priori.

Para a última etapa da ATD, que corresponde à comunicação, foram construídos os metatextos interpretativos e/ou descritivos. Esse é o momento em que o pesquisador expressa sua voz no texto, realiza reflexões, anuncia pontos de vista devidamente fundamentados e opõe-se a outros, além de possibilitar um novo modo de compreender as informações submetidas à análise (MORAES; GALIAZZI, 2011). No entanto, é importante destacar que, na ATD, o pesquisador assume-se como autor das interpretações que constrói, o que contribui para enfatizar a ideia de não neutralidade teórica na pesquisa realizada. Em linhas gerais, a ATD é um exercício de produzir e expressar sentidos (MORAES; GALIAZZI, 2011).

De acordo com a descrição acima, após a transcrição das entrevistas, passou-se a realizar uma leitura flutuante, procurando organizar fragmentos dos depoimentos num movimento convergente aos FADs. A intenção consistia em evidenciar indícios da aprendizagem docente referentes a cada um dos focos, proporcionando as interpretações e as conclusões registradas na próxima seção.

\section{Apresentação e análise dos dados}

A análise dos dados desta pesquisa demonstra que a participação nas atividades desenvolvidas no Pibid/Física proporciona indícios da ocorrência da aprendizagem docente sugerida pelos FADs, como será possível observar na sequência, por meio de fragmentos transcritos dos depoimentos dos participantes.

\section{Foco 1 - Interesse pela docência}

Nesta categoria agruparam-se trechos dos depoimentos dos bolsistas de iniciação à docência que demonstram motivação, empolgação e interesse ao experimentarem atividades desenvolvidas no ambiente escolar.

A análise dos dados evidencia que a participação nas atividades desen- 
volvidas no Pibid/Física foi aprovada por todos os participantes. Para eles, essa consiste em uma oportunidade de aprender elementos novos sobre a docência. Ao ser indagado sobre a avaliação que faz da sua participação no Pibid/Física, B18 revela:

B18: Considero minha participação no Pibid como muito positiva, pois a aprendizagem é tanto para mim quanto para os alunos. É muito bom, porque tu sai ${ }^{1}$ daquela coisa maçante da sala, de só conteúdo e conteúdo, e consegue entender sobre o que é ser professor e se envolver mais com o curso também, e através disso a gente consegue construir uma teoria concreta do que é a profissão de professor.

Nesse mesmo sentido, B6 afirma que fazer parte do programa "é uma experiência muito boa porque na prática se pode ver que existem outros fatores que influenciam na aula e que não se estuda na faculdade [...]".

B18 considera, na mesma perspectiva, que sua participação no Pibid “[...] foi muito proveitosa, porque estar na sala de aula com os alunos do Ensino Médio nos faz entender que ensinar física não é só saber o conteúdo; é necessário também saber interagir com a turma [...]".

Outro elemento muito evidenciado na fala dos bolsistas foi a motivação para a docência proporcionada pela oportunidade de estar no seu futuro ambiente de atuação. Isso pode ser percebido nos comentários de B5 e B8, respectivamente: “[...] estar participando do Pibid está sendo muito tri. É legal ir para a escola, ir para a galera e mostrar a física para eles [...]"; "[...] é muito legal, é muito bom, eu gosto bastante, pois estamos dentro da realidade da escola, vendo como funciona o processo de ensino [...]".

Para B3, a motivação sobre a docência surgiu ao perceber, durante as atividades desenvolvidas no Pibid, que a realidade escolar "[...] é diferente do que os professores do Ensino Médio comentavam, que os alunos não colaboravam, que era difícil ser professor [...], hoje eu não vejo assim, eu vejo como algo motivante. Eu vejo que essa profissão é algo que pode ser sim positivo”.

B10, por sua vez, salienta que o Pibid o levou a perceber que a atividade de professor é interessante e o motivou a saber mais sobre a docência, como se percebe no trecho de seu depoimento:

B10: [...] cursei Engenharia um tempo e, então, trabalhei muitos anos em empresas e depois fui para a física e participei do Pibid. Ali vi que ser professor é diferente da realidade que eu tinha de sala de aula. Hoje eu percebo que eu gosto e quero ser professor. Assim, estou sempre procurando coisas novas na área, e gosto também de saber como preparar aulas práticas, de descobrir uma nova metodologia de ensino [...], então isso é muito bom.

Estar no ambiente escolar possibilita aos bolsistas de iniciação à docência desenvolver interesse sobre a docência, como afirma B16: “[...] fazer parte do Pibid foi algo que motivou mais ainda em querer buscar sobre a atividade de professor. Me ajudou a decidir que depois de formado quero fazer mestrado e doutorado em ensino de Física". 
Para B9, a participação no programa foi uma experiência desafiadora, como comprova o seu relato, transcrito a seguir:

\begin{abstract}
B9: [...] física teórica eu aprendo escrevendo, e é uma coisa um pouco mecânica; matemática, do mesmo jeito... E eu pensava que docência seria simples, como é estudar física. No Pibid eu acabei percebendo que não é assim [...]. Na escola, quando eu tentava ajudar os alunos e via que eles não entendiam, não tinham interesse no que eu falava, isso às vezes me colocava meio para baixo e foi me fazendo ir descobrir por que isso acontecia. Toda essa busca foi me ajudando e agora eu vejo que estou bem melhor do que quando entrei, até na questão de falar, na oratória, consigo manter uma linha de raciocínio. Foi por causa dessas situações que eu tomei a decisão de seguir na profissão de professor e seguir na física [...], porque a ideia que eu tinha era fazer física e ser completamente física teórica e não querer sala de aula. No Pibid, vendo como é complicada a situação dentro de uma sala de aula e vendo como é complexo trabalhar a física com os alunos, me desafiou e me fez tomar essa decisão.
\end{abstract}

A compreensão de que o Pibid pode ser um espaço para confirmação da escolha profissional é compartilhada pela maioria dos entrevistados, como evidenciam estas falas: "[...] não sei se continuaria no curso se não fosse o Pibid, eu acho que não me motivaria [...]” (B1); “[...] no Pibid eu pude ver que é isso mesmo [ser professor] que eu quero [...]” (B19); “[...] eu estava até um pouco indeciso em cursar física porque é um curso difícil. Aí eu entrei no Pibid e isso me animou [...]" (B26); “[...] no Pibid que eu realmente percebi que eu tenho vocação para ser professor. Porque antes era uma vontade que eu tinha, mas não sabia se era realmente a vocação que eu poderia seguir. Então depois do Pibid eu percebi que estou no caminho certo" (B4). O depoimento de B31 também revela essa percepção:

B31: [...] participar do Pibid me fez crescer muito, porque, depois que eu entrei, minhas notas aumentaram, eu comecei a ir bem e decidi que era física que eu queria. Porque quando eu entrei na universidade eu queria Matemática, mas passei na física, mas daí entrei no Pibid e comecei a ter contato mais com os professores e a física mesmo, porque nos encontros a gente resolvia exercícios e experimentos e eu comecei a gostar e ver que era isso que eu queria para a minha vida.

Essas falas convergem na concepção de Nóvoa (2009), ao afirmar que a formação de professores é fortalecida com o trabalho na escola e a vivência de casos concretos. Do mesmo modo, aproximam-se das ideias de Tardif (2012, p. 65), para quem

[...] um professor de profissão não é somente alguém que aplica conhecimentos produzidos por outros, não é somente um agente determinado por mecanismos sociais: é um ator no sentido forte do termo, isto é, um sujeito que assume sua prática a partir dos significados que ele mesmo lhe dá, um sujeito que possui conhecimentos e um saber-fazer provenientes de sua própria atividade e a partir dos quais ele a estrutura e a orienta.

Diante disso, pode-se concluir que a inserção dos acadêmicos no ambien- 
te escolar ao longo de sua formação proporciona motivação e interesse pela docência, evidenciando indícios da aprendizagem docente relacionada aos elementos do Foco 1.

\section{Foco 2 - Conhecimento prévio da docência}

Para Nóvoa (2006), o lugar da formação de professores, por excelência, é a escola, onde ocorre a diversificação dos modelos e das práticas, instituindo novas relações dos professores com o saber pedagógico e científico que passam pela experimentação, pela inovação, pelo ensaio de novos modelos de trabalho pedagógico. Nesse sentido, reuniu-se, nesse foco, parte dos depoimentos dos bolsistas de iniciação à docência que descrevem as atividades desenvolvidas no decorrer da participação no Pibid/Física. Segundo seus relatos, essas atividades incluem observação de aula, monitoria e reforço em turno inverso, além de auxílio aos supervisores na resolução de exercícios e na explicação dos conceitos físicos. Todas essas atividades são compreendidas pelos acadêmicos como a oportunidade de adquirirem uma vasta bagagem docente e pedagógica, conforme salienta B9:

B9: [...] as atividades que realizamos no Pibid não vão servir só para o Pibid. Hoje, além de ser bolsista, eu também já dou aula - assumi um contrato emergencial do Estado - e tudo o que fazemos no projeto acabo aplicando também nas minhas aulas. As aulas práticas, as listas de exercícios, os textos discutidos, a retomada dos conteúdos [...].

A mesma concepção é evidenciada por B30 em sua fala: “[...] tudo o que eu vivenciei no Pibid, com toda certeza, vou poder usar novamente quando estiver trabalhando como professor [...]".

Para B10, a participação no programa possibilitou desenvolver habilidades para resolver problemas que ocorrem no interior da sala de aula: "[...] numa sala de aula sempre tem problemas e ocorrem imprevistos, mas quanto mais experiência a gente tiver, mais a gente vai conseguir contornar esses problemas e lidar com os imprevistos". Essas experiências que brotam da experiência cotidiana do ambiente escolar são consideradas por Tardif (2012) como saberes experimentais e que somente são desenvolvidos pelos professores ou futuros professores no exercício das atividades da docência.

Vivenciar o cotidiano do ambiente escolar possibilita que os bolsistas percebam como vem ocorrendo o processo de ensino de física nesse contexto, como relata $\mathrm{B} 26$ :

B26: [...] estar no Pibid me fez ver que nem sempre os estudantes estão dispostos a estudar. Muitas vezes estão cansados, desanimados, pois trabalharam o dia inteiro. Mas, também, as aulas quase sempre são iguais, não têm nada de diferente... Não tem aula prática, os conteúdos são quase sempre matemáticos e com muitas fórmulas.

Tal percepção, que é compartilhada por muitos participantes, levou a atividade mais destacada nas suas falas corresponder ao planejamento, à elaboração, 
à construção e à implementação de roteiros de atividades experimentais, na busca da contextualização dos assuntos físicos estudados, como destaca B3:

B13: [...] percebendo a dificuldade dos alunos do Ensino Médio em entender física, percebemos que precisávamos mostrar para eles onde a física está no seu dia a dia, relacionando os conteúdos com o mundo onde se vive. E achamos que a melhor forma de conseguir isso é fazendo atividades experimentais.

Relacionado a essa fala, B16 menciona o fato de que a escola não tem laboratórios, mas que as atividades experimentais podem favorecer a aprendizagem e a contextualização. Diante desse descompasso, os bolsistas precisam construir os materiais necessários para a realização dessas experimentações, ampliando o rol de aprendizagens provenientes do programa.

B16: [...] a escola onde participo no Pibid não tem laboratórios de física, e nós achamos que fazer aulas práticas ajuda muito os alunos a entenderem melhor os conteúdos trabalhados em sala de aula. Então a gente elabora atividades principalmente de caráter investigativo e experimental [...], a gente acaba criando as atividades experimentais. Como no Pibid não se pode comprar equipamentos experimentais prontos, temos que construir os equipamentos que vamos utilizar. Considero isso bom, porque, além de pensarmos como vamos usar eles para que os alunos aprendam, também aprendemos a cortar, colar, construir. Tudo isso vai nos ajudar depois de formados [...].

A confecção de equipamentos para atividades práticas utilizando materiais alternativos também é comentada por B18: “[...] nos experimentos utilizamos material alternativo, então construímos os equipamentos, organizamos uma estratégia de ensino e levamos para a escola [...]". Nesses trechos, percebe-se que o reconhecimento das limitações do ambiente escolar leva os bolsistas a buscarem alternativas para o enfrentamento dos problemas cotidianos, adquirindo experiências didáticas, metodológicas e pedagógicas que orientarão suas futuras atuações.

No entanto, não foi apenas com atividades experimentais que os licenciandos buscaram a contextualização dos conceitos estudados. Os bolsistas salientam que, no decorrer das atividades desenvolvidas no programa, recorreram à demonstração de fenômenos físicos por meio de simuladores disponíveis na internet, leitura e discussão de textos científicos, planejamento, organização e realização de eventos, como feira de ciências, clube de ciências e oficinas abordando variados temas relacionados com a física. Como exemplo, pode-se citar oficinas de fotografia, de utilização de software no ensino de física, de utilização de plataforma de prototipagem eletrônica do tipo arduino em experimentos, de discussão da importância das mulheres na ciência e de conceitos físicos através de histórias em quadrinhos. Atividades lúdicas, como jogos que envolvem conteúdos relacionados com a física, também foram mencionados, como evidencia a fala de B11:

B11: [...] desenvolvemos atividades mais lúdicas, pois é uma forma de estudar a física com uma nova visão, brincando e aprendendo ao mesmo tempo. [...]. Eu tenho desenvolvido jogos, como o da Termodinâmica, que é um jogo de trilha onde os alunos devem relacio- 
nar o conteúdo [...], com isso eles vão aprendendo e eu aprendo também, pois na hora de pesquisar eu estou junto para conseguir montar, porque eu tenho que ter o conhecimento para ajudar eles $[\ldots]$.

Outro elemento bastante mencionado nas entrevistas diz respeito à busca pela interdisciplinaridade nas atividades desenvolvidas, como salienta B4: “[...] as oficinas realizadas devem envolver temas interessantes. Assim, nos reunimos com os Pibid de outras áreas, como o da Matemática, o da Química, e abordamos o tema completamente". No depoimento de B7 é citado outro exemplo que demonstra a busca pela interdisciplinaridade: “[...] a gente primeiro elaborou uma oficina de fotografia. Mas percebemos que a física não conseguia explicar tudo sobre o tema, assim, convidamos o Pibid da Química e a oficina foi um sucesso!”.

No fragmento da entrevista de B18, transcrito a seguir, verifica-se um exemplo de atividade interdisciplinar que está sendo realizada por seu subprojeto. $\mathrm{Na}$ mesma fala, pode-se perceber a validade dessa experiência para a formação profissional do estudante:

B18: [...] estamos agora desenvolvendo um projeto interdisciplinar que engloba muitas áreas, eu devo falar sobre vasos sanguíneos, sobre raios ultravioletas e essas coisas. Cada área fala um pouco sobre o que o assunto tem sobre sua disciplina, e os alunos do Ensino Médio têm que identificar as áreas. Isso tudo acaba sendo bem importante, pois estou aprendendo muito com os colegas dos outros cursos e fortalecendo meus conhecimentos [...]. O Pibid aqui abrange 16 áreas, então é muito bom conversar com o pessoal das $\mathrm{Hu}-$ manas, porque cada um passa um pouco de sua área [...], a gente vai conseguindo chegar numa aula e não falar só de física [...].

Os aspectos identificados nas entrevistas vão ao encontro dos pressupostos de Tardif (2012, p. 36), para quem os professores formam um grupo social e profissional que, para existir, precisa dominar, interagir e mobilizar os saberes docentes, compreendidos pelo autor como "um saber plural, formado pelo amálgama, mais ou menos coerente, de saberes oriundos da formação profissional e de saberes disciplinares, curriculares e experimentais". Ainda, os relatos analisados comungam com a concepção de Nóvoa (2009), ao defender que, na transição de acadêmico para professor, é fundamental consolidar as bases de formação no acompanhamento do ambiente escolar e na análise de situações concretas.

Logo, pode-se concluir que participar das atividades desenvolvidas no Pibid/Física contribui para que os bolsistas conheçam, na ação, a realidade escolar e, com base na reflexão na ação, desenvolvam conhecimento de casos e adquiram um repertório de experiências didáticas e pedagógicas que orientarão a sua futura atuação profissional, apresentando, dessa forma, indícios da aprendizagem sugerida pelo Foco 2. Também é possível perceber, nos depoimentos analisados, que, evidenciando os problemas presentes no ambiente escolar, os bolsistas buscam alternativas para minimizá-los, o que indica a aprendizagem referente ao Foco 3. $\mathrm{Na}$ sequência, apresentam-se e comentam-se outros trechos das entrevistas que relacionam a aprendizagem sugerida por esse foco. 


\section{Foco 3 - Reflexão sobre a docência}

Nas palavras de Pimenta (2005, p. 26),

[...] os saberes teóricos propositivos se articulam [...] aos saberes da prática, ao mesmo tempo ressignificando-os e sendo por eles ressignificados. O papel da teoria é oferecer aos professores perspectivas de análises para compreender os contextos históricos, sociais, culturais, organizacionais, e de si mesmos como profissionais, nos quais se dá sua atividade docente, para neles intervir, transformando-os. Daí é fundamental o permanente exercício da crítica nas quais o ensino ocorre.

Assim, os trechos das entrevistas que compõem essa categoria referem-se ao planejamento, à elaboração e à execução de ações no ambiente escolar permeados pelo processo de ação-reflexão-ação. Nesses relatos, o trânsito e a articulação entre teoria e prática recebem especial atenção, isto é, ganham ênfase as falas dos bolsistas que evidenciam a sua participação em situações de estudo em busca de soluções para os problemas detectados durante a execução das atividades no ambiente escolar.

O planejamento e a elaboração das atividades a serem desenvolvidas no ambiente escolar são realizados em grupo, e o espaço mais frequente para essas atividades consiste nos encontros organizados nas instituições de ensino superior (IES). Como relata B9, “[...] a gente prepara as aulas junto com a coordenação de área e a supervisora aqui na universidade. Primeiro vemos o que está sendo dado na matéria, os conteúdos abordados [...], então a gente faz a preparação”. O exposto é reforçado por B7:

B7: [...] a gente costuma se reunir semanalmente, discutir entre os colegas, com as supervisoras e com a coordenadora, a gente debate o que vai ser passado na sala de aula nas escolas, e sempre fazendo tudo de acordo com o que as escolas vão trabalhar. Organizamos as atividades de laboratórios, os exercícios, as formas de explicar através do que o ambiente permite. Nesses encontros também avaliamos o que deu certo e o que não deu quando a gente aplicou. Aquilo que deu errado, ou que não conseguimos explicar voltamos, procuramos em livros, na internet e alteramos para poder melhorar nossa prática.

Como se percebe na fala do participante, os encontros nas IES também são destinados a reflexões em busca de soluções para os problemas e/ou dificuldades identificados pelos bolsistas no ambiente escolar. Esses problemas e/ou dificuldades podem ser de diferentes ordens - conceituais, metodológicas, indisciplinas de estudantes, postura de docente -, como evidencia o trecho da fala de B4: “[...] já me deparei com situações que não lembrava de determinados conceitos quando estava apresentando as oficinas planejadas [...], então nos encontros na universidade tentei pesquisar para na próxima vez isso não acontecer [...]”. B26 socializa, em sua fala, uma situação semelhante: "[...] isso acontecia bastante [não saber/lembrar conteúdos], outra coisa que acontecia bastante era de eu não saber como agir em determinadas situações quando estava dando aula, mas nos encontros na universidade eu pedia ajuda e hoje melhorei muito [...]". 
B5 relata que, certa vez, ao ministrar uma oficina, percebeu que a turma não prestou atenção e se agitou bastante, o que o levou a solicitar ao coordenador de solicitar auxílio de como proceder nesta situação ao coordenador de área. Os depoimentos demonstram que os coordenadores de área e os supervisores dão suporte e indicam referenciais teóricos e metodológicos aos bolsistas, para que eles sejam capazes de enfrentar as dificuldades detectadas. Isso pode ser observado, também, na fala de B4:

B4: [...] aí se aparece alguma dúvida no conteúdo que estamos trabalhando, ou surge algum tipo de situação diferente, a gente comenta nas reuniões na universidade e também com os supervisores na escola. Eles nos orientam, sugerem materiais para pesquisarmos e assim vamos aprendendo com isso.

$\mathrm{Na}$ mesma perspectiva, B3 exemplifica:

B3: [...] nestes últimos tempos, muito tem se falado em interdisciplinaridade, o que tem feito com que nós precisemos saber coisas de outras áreas. Assim, nas reuniões, os supervisores e o coordenador ajudam a gente a não buscar conhecimento só na própria área, mas também conhecimentos em outras áreas. [...] depois o coordenador trouxe alguns artigos científicos sobre o que realmente é interdisciplinaridade. Isso foi muito bom porque percebi que fazer interdisciplinaridade não é só saber os conteúdos de outras áreas, e sim entender como eles estão interligados, pois no mundo verdadeiro os conteúdos não estão separados.

Em sua fala, B2 revela o que faz ao se deparar com dificuldades no desenvolvimento das atividades planejadas: “[...] a gente vai até os supervisores e o coordenador e eles indicam vários referenciais, então a gente olha vários livros, então isso cresce também na parte conceitual, você começa a comparar várias formas de trabalhar, analisa qual a melhor ou qual pode dar mais certo".

Dentre as fontes consultadas pelos bolsistas de iniciação à docência na busca de soluções sobre os problemas enfrentados no ambiente escolar, destacam-se os livros didáticos, sites de física disponíveis na internet e em laboratórios virtuais, textos científicos sobre teorias de aprendizagem, sobre epistemologia, sobre as diferentes fases do desenvolvimento cognitivo humano, sobre neurociências e sobre formação de professores. Ainda é muito salientada a consulta a periódicos eletrônicos que apresentam textos de desenvolvimento de experiências pedagógicas da área de física.

Todas essas atividades de busca e de fundamentação possibilitam que os bolsistas, juntamente com seus supervisores e coordenadores de área, desenvolvam e testem novas estratégias de ensino para suprir as dificuldades encontradas. É o que evidencia a fala de B8:

B8: [...] percebemos uma realidade em que os alunos não gostavam das aulas de física [...], então a gente começou no Pibid a elaborar atividades que proporcionavam a possibilidade de eles criarem as coisas, de tirar a visão de continhas e se preocupar mais com a visão 
dos conceitos e da física real [...]. Tudo isso foi elaborado a partir de alguns trabalhos de pesquisadores [...] e hoje percebemos que deu certo, pois eles [os estudantes do Ensino Médio] estão entendendo melhor.

Outro elemento importante percebido na fala dos bolsistas diz respeito à compreensão da dinâmica de uma sala de aula, levando os acadêmicos a entender que os estudantes de nível médio podem aprender de várias formas e em diferentes lugares, como menciona B10:

B10: [...] vivenciar o Pibid e estudar como se ensina e como se aprende me tirou da cabeça que os alunos só aprendem quando reproduzem um montão de exercícios parecidos com aqueles que o professor explicou. Hoje percebo que a aula pode ser bem mais legal. Então, levamos vídeo, experimentos, demonstrações, fazemos atividades no pátio da escola e percebemos que eles entendem bem, pois falam sobre o que está ocorrendo, fazem hipóteses, demonstram que entenderam [...].

O trecho a seguir, transcrito da fala de B15, demonstra que a estrutura organizada nos subprojetos do Pibid/Física pode proporcionar uma reflexão orientada pela ação: “[...] durante a elaboração de alguma atividade didática eu começo a pensar em todas as teorias estudadas até então, o que levou o autor a pensar naquilo e começo a entender que não existe prática sem teoria”. Esse relato vai ao encontro das palavras de Nóvoa (1992, p. 23), ao observar que

[...] a dinamização de dispositivos de investigação-ação e de investigação-formação pode dar corpo à apropriação pelos professores dos saberes que são chamados a mobilizar no exercício de sua profissão. A este propósito é útil conjugar uma formação do tipo clínico, isto é, baseada na articulação entre a prática e a reflexão sobre a prática, e uma formação do tipo investigativo, que confronte os professores com a produção de saberes pertinente. O esforço de formação passa sempre pela mobilização de vários tipos de saber: saberes de uma prática reflexiva; saberes de uma teoria especializada; saberes de uma militância pedagógica.

Assim, conclui-se que as atividades desenvolvidas no âmbito do Pibid/ Física proporcionam espaços propícios para que o futuro professor possa se dedicar a uma reflexão mais sistemática e aprofundada sobre os fatos ocorridos em sala de aula, sobre os momentos em que, atento ao raciocínio do aluno, agiu de uma determinada forma, avaliando as atitudes tomadas. Essa é a reflexão sobre a reflexão na ação, uma análise que o futuro professor, dispondo de tempo e munido de instrumentos teóricos, faz posteriormente sobre o seu conhecimento e seu desempenho docente. A reflexão aqui se aproxima de uma atividade de pesquisa. Trata-se de uma investigação sobre a própria prática, "colocando as bases para o que se convencionou denominar o professor pesquisador" (PIMENTA, 2005, p. 20). Dessa forma, constata-se que, ao participar do programa, os acadêmicos adquirem aprendizagens docentes referentes ao Foco 3. 


\section{Foco 4 - Comunidade docente}

O diálogo entre professores e futuros professores é fundamental para consolidar saberes emergentes da prática profissional (NÓVOA, 2009). Nesse sentido, a criação de redes coletivas de trabalho constitui, também, um fator decisivo de socialização profissional e de afirmação de saberes próprios da profissão docente. Para Nóvoa (1992, p. 13),

[...] é importante a criação de redes de (auto)formação participada, que permitem compreender a globalidade do sujeito, assumindo a formação como um processo interativo e dinâmico. A troca de experiências e a partilha de saberes consolidam espaços de formação mútua, nos quais cada professor é chamado a desempenhar, simultaneamente, o papel de formador e de formando.

Com base nessa concepção, agruparam-se, nesse foco, trechos das entrevistas que demonstraram momentos do Pibid/Física destinados à partilha de experiências adquiridas no ambiente escolar durante o desenvolvimento das atividades do programa.

Como já evidenciado, os dados indicam que os bolsistas planejam e executam as atividades do programa sempre em grupos e que a elaboração dessas atividades se dá nos encontros semanais que ocorrem nas IES. No entanto, esses momentos também se destinam à partilha das experiências vivenciadas, como relata B4: "Existe uma reunião por semana onde todos os pibidianos se juntam para falar sobre a experiência vivenciada naquela semana [...]". Tal sistemática apresenta-se na fala de todos os entrevistados, demonstrando que o encontro nas IES, paralelamente a outros objetivos, visa habituar os alunos, futuros professores, a práticas reflexivas.

Sobre esses encontros, afirma B13: "[...] ao ouvir os colegas pibidianos, aprendemos muito, pois no grupo acabamos trocando muito. $\mathrm{O}$ fato de ouvir o colega contando o que fez, a gente pode se espelhar ou rever o que pode fazer para melhorar [...]". Nesses espaços, a participação dos supervisores e coordenadores também é bastante salientada pelos bolsistas, como pode se perceber nas falas a seguir: "a professora supervisora também troca experiências conosco. Ela ouve nossas angústias, nossos medos, nossas pequenas experiências [...], então ela nos dá dicas de como trabalhar e nos passa muita segurança [...]” (B21); “[...] a própria professora coordenadora fica com a gente, ela fala sobre o que já aconteceu com ela, faz comparação com o que acontece conosco e relaciona com os estudos dos teóricos da educação [...]" (B26).

Percebe-se, nos depoimentos, que a avaliação das atividades implementadas é o ponto de partida para o relato e a partilha das experiências dos bolsistas no ambiente escolar, a exemplo da fala de B17: "[...] nos encontros na universidade fazemos uma avaliação onde os colegas, o professor e os supervisores sugerem, e daí, se precisa alguma modificação, a gente faz".

Em se tratando da sistematização desses relatos, B2 menciona a existência de um caderno de registros das atividades para posterior avaliação: 
B2: [...] temos um diário de bordo ou caderno de memória onde a gente faz a descrição da nossa prática, o que não deu certo, aí a gente vai lá e escreve o que não deu certo, e porque não deu, então a gente trabalha em cima do nosso erro. Nos encontros da semana, a gente comenta com colegas, com a professora e com as supervisoras. Então, depois a gente trabalha para que esse erro não ocorra mais [...].

Conforme o trecho da entrevista de B6, transcrito a seguir, as partilhas de experiências nas escolas envolviam, além dos bolsistas, outros personagens do ambiente escolar:

B6: [...] outro momento em que ocorria a troca de experiências era no intervalo, na sala de professores. Lá eu era um dos que interagiam bastante [...], uma coisa que me chamava atenção era que alguém de nós da física conversava com professores de português, com o pessoal da química, de artes, sobre o que nós fazíamos e estudávamos. Aí eles contavam o que estavam trabalhando e falando de situações que aconteciam com eles [...], até teve uma atividade que foi feita junto com a área da Química que surgiu a partir de uma conversa na sala dos professores, então foi interessante essa partilha.

Sobre a validade desses momentos, B16 destaca:

B16: [...] eu considero muito importante, porque a gente vê as atividades que são muito boas e vê as que são um fracasso. A gente imagina uma coisa, mas na hora de fazer a atividade toma outro rumo e não sai com a gente queria, então [...] eu acho importante depois fazer uma autorreflexão sobre as atividades, então a gente consegue aprender com os nossos próprios erros $[\ldots]$.

Na mesma perspectiva, B32 acredita que

B32: [...] são momentos como estes que nos fazem trocar figurinhas, aprender com os colegas, criar bagagem profissional e aprender coisas que talvez não se aprenda na faculdade [...] ouvindo os colegas a gente percebe que tem coisas que ocorrem com todos e que cada um age de uma forma, então precisa prestar atenção, pois se um dia acontecer com a gente podemos usar a estratégia do colega. Então, ter um espaço que permita falar com os colegas sobre o que foi feito te deixa mais seguro e ainda permite que a gente aprenda se apoiando uns nos outros.

Evidencia-se, nesses trechos, que, entre as atividades desenvolvidas pelo Pibid/Física, está a análise coletiva das práticas, enquanto rotina sistemática de acompanhamento, de supervisão e de reflexão sobre o trabalho docente. Nesse espaço, busca-se fazer a profissão evoluir de uma dimensão individual para uma dimensão coletiva, transformando a experiência do grupo em conhecimento profissional. Nesse sentido, conclui-se que os bolsistas de iniciação à docência apresentam indícios de aprendizagem docente referente ao Foco 4, por terem vivenciado situações de partilha e troca de experiências que, segundo Nóvoa (2009) e Tarfif (2002), são as atividades que contribuem para a emancipação profissional e a consolidação de uma profissão autônoma na produção dos seus saberes e dos seus valores. 


\section{Foco 5 - Identidade docente}

Este foco reúne trechos das entrevistas que demonstram a construção de uma identidade docente nos bolsistas de iniciação à docência mediante a sua participação nas atividades desenvolvidas no Pibid/Física.

Mesmo já tendo participado de diversas situações envolvendo a discussão e a reflexão do ser professor, o planejamento e a elaboração de estratégias de ensino, a construção de materiais didáticos, a implementação de atividades no ambiente escolar e o processo de avaliação das atividades desenvolvidas, aos serem indagados se já se sentem professores, todos os pesquisados afirmaram que não, uma vez que ainda existem muitos conhecimentos a serem adquiridos. De acordo com a sua fala, B16 se considera "[...] um professor ainda em formação [...]", concepção compartilhada por B20, que afirma:

B20: [...] eu acredito que tenha muita coisa que eu preciso aprender de física e sobre como ensinar essa física [...], no Pibid as minhas aulas são mais para ajudar os alunos e não para ensinar os alunos. Então, eu preciso aprender mais essa parte para ser um professor de verdade [...].

B18 reforça essa percepção em sua fala:

B18: [...] eu não digo pronto, eu acho que não, eu preciso bastante ainda, por mais que eu já tenha cursado mais da metade do curso, esteja na sala de aula com o Pibid [...]. O Pibid me ajudou a perceber que para ser professor é preciso ter maturidade e segurança para enfrentar uma turma para conseguir desenvolver os conteúdos, isso eu melhorei muito, mas preciso de mais tempo para alcançar este patamar [...].

Para B25, participar do Pibid/Física lhe possibilitou melhorar em vários aspectos do ser professor, como se verifica no trecho de sua entrevista transcrito a seguir:

B25: [...] nesses dois anos de participação no Pibid eu melhorei muito, mas ainda não me considero um professor. Preciso apender muito ainda sobre o que é ser um professor de verdade [...], mas já sei elaborar uma aula, sei que nem sempre tudo o que se planeja dá certo, que cada aluno é um, que a escola é dinâmica e cheia de imprevistos, que falta material para dar, que muitos professores não levam a sério sua profissão, faltando mesmo sem muita necessidade, que tem buracos na sala, enfim, sei bastante do que deve ser feito por um professor, como ser ético, por exemplo. Mas preciso aprender muito mais de conteúdos, de como lidar com esses imprevistos, com a indisciplina dos alunos. Então vou estudando para ver se um dia eu chego lá.

Os bolsistas, ao perceberem-se como professores em formação, apresentam a compreensão de que o sujeito constrói seu saber ativamente, ao longo do seu percurso de vida. Nessa perspectiva, as análises das entrevistas evidenciam indícios da aprendizagem docente relativa ao Foco 5, uma vez que os dados obtidos vão ao encontro do entendimento de Pimenta (2012), que considera a identidade como construção do sujeito, situado no tempo e no espaço, que passa pelo confronto entre as teorias e as práticas vigentes, bem como por uma revisão das tradições, das tarefas e do próprio significado que o sujeito dá ao seu ofício. 


\section{CONSIDERACְÕES FINAIS}

Os dados obtidos nesta pesquisa conduzem a concluir que os acadêmicos de licenciatura em física de instituições gaúchas, ao participarem das atividades do Pibid/Física na condição de bolsistas de iniciação à docência, vivenciam situações que promovem a aquisição das aprendizagens relacionadas aos FADs. Com efeito, evidenciou-se, nos relatos analisados, que, no decorrer das atividades, os bolsistas adquirem conhecimento prático da docência por meio da ação e com base na reflexão na ação, ampliando seu interesse pela área. Na elaboração, na implementação e na avaliação das atividades, trabalham a capacidade de refletir sobre a docência e de partilhar experiências com colegas e demais personagens do processo de ensinar e aprender, desenvolvendo, dessa forma, a reflexão coletiva. Ainda, identificando-se como aprendizes da docência, procedem à construção de sua identidade docente.

Esses resultados se aproximam dos obtidos por trabalhos semelhantes encontrados na literatura, como, por exemplo, o de autoria de Moryama, Passos e Arruda (2013), no qual os pesquisadores também constataram indícios da aprendizagem sugerida pelos FADs em um grupo de 19 bolsistas de iniciação à docência de um subprojeto de Biologia desenvolvido na Universidade Estadual de Londrina (UEL). Em outro trabalho, Piratelo, Passos e Arruda (2014) identificaram, em um grupo de cinco licenciandos em física da UEL, que a participação nas atividades do Pibid naquela universidade levou a que esses estudantes aprendessem mais

sobre a docência, interessando-se por ela; conhecendo e se apropriando de um repertório de possibilidades para a realização de intervenções práticas em sala de aula; refletindo a respeito das situações de gestão do conteúdo e de gestão de classe; engajando-se em uma comunidade escolar e professoral; e, por fim, identificando-se com o exercício da docência (PIRATELO; PASSOS; ARRUDA, 2014, p. 514).

Com base nos resultados apresentados e nos trabalhos correlacionados aqui referidos, conclui-se que, na formação de professores, o desafio consiste em conceber o ambiente escolar com um ambiente educativo, onde o trabalhar e o formar não sejam atividades distintas. Como salienta Nóvoa (2009, p. 26), “a formação de professores deve ser construída dentro da profissão [...] baseada na combinação complexa de contributos científicos, pedagógicos e técnicos, mas que tem como âncora os próprios professores". Não se quer dizer com isso que a Universidade não desempenhe um papel fundamental na formação de professores. Ela é a responsável pela sustentação científica, pela produção cultural e por todo o embasamento teórico. O que os resultados deste estudo apontam é que a aproximação da universidade com o ambiente escolar - um dos objetivos do Pibid - pode fortalecer os saberes necessários para a futura atuação profissional desses acadêmicos. 


\section{NOTAS}

${ }^{1}$ Registra-se, neste texto, a fala espontânea dos entrevistados.

\section{REFERÊNCIAS}

ARRUDA, S. M., PASSOS, M. M., FREGOLENTE, A. Focos da aprendizagem docente. Alexandria - Revista de Educação em Ciência e Tecnologia, Florianopolis, v.5, n.3, p. 25-48, 2012.(INFORMAR v.X, n.X.)

CAPES. Portaria no 096, de 18 de julho de 2013. Aprova o Regulamento do Programa Institucional de Bolsa de Iniciação à Docência. Diário Oficial da União. Brasília, 2013. Disponível em: < https://www.capes.gov.br/images/stories/download/legislacao/Portaria_096_18jul13_AprovaRegulamentoPIBID.pdf>. Acesso em: 18 out. 2015.

CRESWELL, J. W. Investigação qualitativa e projeto de pesquisa: escolhendo entre cinco abordagens. 3. ed. Port o Alegre: Penso, 2014.

DEBALD, B. S.; ROVARIS, D. Nóvoa: o professor, sua formação e a práxis. Pleiade, Foz do Iguaçu, v. 1, n. 2, 1(2), p. 111-118, 2007. Disponível em: < http://www. uniamerica.br/site/re vista/index.php/pleiade/article/view/64/55>. Acesso em: 03 mar. 2015.

LEVY, M. I. C.; SANMARTÍ PUIG, N. Fundamentos de un modelo de formación permanente del profesorado de ciencias centrado en la reflexión dialógica sobre las concepciones y las prácticas. Enseñanza de lãs Ciencias,Barcelona, v.19, n.2,p. 269-283, 2001.

MORAES, R. Uma tempestade de luz: a compreensão possibilitada pela análise textual discursiva. Ciência \& Educação, Bauru, v. 9, n. 2, p. 191-211, 2003.

MORAES, R.; GALIAZZI, M. C. Análise textual discursiva. Ijuí: Unijuí, 2011.

NÓVOA, A. (Coord.). Os professores e a sua formação. Lisboa: Dom Quixote, 1992.

NÓVOA, A. (Org.). Profissão professor. Porto: Porto, 1999.

NÓVOA, A. Desafios do trabalho do professor no mundo contemporâneo. 2006. Disponível em: <http://www.ergonomia.ufpr.br/Metodologia/RBDE13_05_ MAURICE_TARDIF.pdf $>$. Acesso em: 18 out. 2015.

NÓVOA, A. Para una formación de profesores construida dentro de la profesión. Revista de Educación, Madri, 350, p. 203-218, 2009.

PIMENTA, S. G. (Org.). Saberes pedagógicos e atividade docente. 4. ed. São Paulo: Cortez, 2005.

PIMENTA, S. G. O estágio na formação de professores: unidade, teoria e prática. São Paulo: Cortez, 1997.

PIMENTA, S. G. O estágio na formação de professores: unidade, teoria e prática. 11. ed. São Paulo: Cortez, 2012.

PIRATELO, M. V. M., PASSOS, M. M.; ARRUDA, S. M. Um estudo a respeito das evidências de aprendizado docente no Pibid da licenciatura em Física. Caderno Brasi- 
leiro de Ensino de Física,Florianópolis, v. 31, n. 3, p. 493-517, 2014.

TARDIF, M. Saberes profissionais dos professores e conhecimentos universitários: elementos para uma epistemologia da prática profissional dos professores e suas consequências em relação à formação para o magistério. Revista Brasileira de Educação, Curitiba, v. 13, 2000. Disponível em: <http://www.ergonomia.ufpr.br/Metodologia/RBDE13_05_MAURICE_TARDIF.pdf>. Acesso em: 5 abr. 2015.

TARDIF, M. Saberes docentes e formação profissional. 13. ed. Petrópolis, RJ: Vozes, 2012.

TARDIF, M.; RAYMOND, D. Saberes, tempo e aprendizagem do trabalho no magistério, Educação \& Sociedade, Campinas, v. 21, n. 73, 2000.

TRIVIÑOS, A. N. S. Introdução à pesquisa em ciências sociais: a pesquisa qualitativa em educação. São Paulo: Atlas, 1987.

Data do recebimento: $13 / 06 / 2015$

Data de aprovação: 26/10/2015

Data da Versão Final: 30/10/2015

\section{Contato:}

Luiz Marcelo Darroz

Rua Coronel Chicuta, 525, Apto 1702.

CEP 99010 - 051

Passo Fundo - RS

E-mail: Idarroz@upf.br 